\title{
The Literature Review of Relationship between Work Family Conflict and Job Performance
}

\author{
Luo Kui ${ }^{1, a^{*}}$ \\ ${ }^{1}$ School of Management Wuhan University of Technology Wuhan, P.R.China \\ a379733643@qq.com
}

\begin{abstract}
Keywords: Work-family conflict; Family-work conflict; Job performance; COR theory; Work demand- resource model
\end{abstract}

\begin{abstract}
Based on the research of the relationship between work-family conflict and job performance literature review analysis, we found the relationship between work family conflict and job performance are diverse. This paper first summarizes the research about the relationship between work family conflict and job performance based on the two theories:COR theory and the work demand - resource model. Secondly points out that the future literature can follow the following three aspects: one is to consider work family conflict affect the job performance through mediation variables, second is considering regulating variable in the mechanism of action of work family conflict affect job performance, three is to consider the research about work family conflict and job performance of the relationship between the different dimensions. In general the future needs more empirical research to study the relationship between work family conflict and job performance.
\end{abstract}

\section{Introduction}

Work and family are two important fields in adult social life [1],when the employees participate in the work role and family role, as a result of the limitation of time,energy and other resources, it will make them unable to perform the responsibilities of these two roles, and then it will produce conflict between the two roles[2].Work family conflict are often used to describe the relationship between work and family.Work family conflict is defined as a kind of role conflict,the conflict generated by pressure from family and work roles in some places are incompatible[3].Research work in family relationship between two different kinds of conflicts were defined,one is work - family conflict(WFC), another is family-work conflict (FWC) [4]. Some scholars pointed out that the employee relationship balance between family and work directly affect the employee's performance[5], as a result of rapid change of competitive environment make the organization have to revaluate the way they manage employee [6],looking forward to the role of staff to provide organizations with more behavior,both within and outside the role to improve the performance of work[7].And according to Motowidlo and Bornman[8]proposed a two-dimensional performance model,performance package task performance and the performance of these two dimensions around. Task performance within the defined roles related to the specific job performance and task performance from the staff's cognitive ability, knowledge, work task efficiency and work experience[9], the surrounding performance is defined as employees work outside the role to support the development of the organization behavior brought about by the performance[10].So companies understand family relationships work efficiency is of great significance to its business operations[11].Through the analysis of the related literature in recent years, this paper attempts to review for nearly three years of work family conflict and job performance of the relationship between existing studies, and indicate the direction for future research.

\section{Conceptual Background}

Resources protection theory (COR) as the research work family conflict and employees' individual output provides a good theoretical framework, COR model proposed individuals tend to get and save resources, these resources is defined as the individual value or can help achieve the goal of the 
material, personal traits, environment and energy, etc.[12]. Employees after work family conflict when these resources will be used to handle and solve the individual facing the difficult[13], at this time will consume resources, such as time, physical and mental, the consumption of these resources can lead to employee unable to perform duties or family responsibilities, this will bring some negative consequences, such as job performance.

Research the basic theory of relation between family relationships and the outcome variables include job requirements - resource model (job demand - resource, JD - R), the model is suitable for a variety of professional and organization, and widely used in the study of occupational stress, it is used to explain how it can affect the health of their employees working conditions and work results) (for example, organizational commitment and job performance, job requirements and resources according to the model is working characteristic of two different categories, and corresponding to the two different processes: health damage process and incentives[14,15]. Work family conflict is an example of job requirements and the social support at work and performance feedback is an example of a work resource[16],so you can use the health damage process explain employees work family conflict mechanism of effects on job performance.

\section{Study on the Relationship between the Work Family Conflict and Job Performance}

Heather n.[17] on the basis of resource conservation theory, through the research on family relationships in the organization work intermediary role in the process of family resources affect job performance, find work family conflict (WFC and FWC) and task performance, organizational support performance, team performance and responsibility, there is no significant correlation relationship between the author when choosing a job performance dimensions, choose a variety of different types of dimensions, expand the scope of work family conflict and work performance research. The authors explain the results of a sample is mainly women, men and women in the use of resources balance work family responsibilities and results in a different way, may lead to the different work family conflict and work performance, future research these differences need to be taken into account.

A study in Korean employees as samples[16]ound that WFC has a negative effect on job satisfaction, job satisfaction has a positive effect on job performance; FWC has a positive effect on job satisfaction and positive affect job performance, the author thinks that employees may be in order to avoid pressure from family, concentrate on work, makes when employees experience FWC job satisfaction will improve, and promote the work performance of ascension. But the author did not examine work family conflict on job performance directly affect, or job satisfaction in the work family conflict affect the task performance mechanism plays a mediating role of assumptions, its measurement performance USES Babin and Boles[17]containing five item of scale development, so the research on its future development accordingly. Mentioned in the article the author also affected by the "Confucius" culture, South Korea, the safeguard of the individual for family values is very seriously, under the condition of this kind of culture, could affect the relationship between the work family conflict and work performance, so the research work in China the relationship between work-family conflict and work performance, culture the situational variables need to be considered.

Osman M.K aratepe[14] to Romania as samples in the study of employees, based on the theory of JD - R model, using the method of structural equation model to verify the emotional exhaustion in the work family conflict (WFC, FWC) affect the work performance of complete mediation effect, and found that women have higher job performance. Measuring performance with Babin and Boles (1998) containing five item of scale development, the scale to measure the task performance, find work family conflict and no significant relationship between task performance, but the work family conflict can pass intermediary variables affect the task performance, for the research of the relationship between work family conflict and work performance provides a new enlightenment.

Christoph Nohe etc. [18],using the way of daily found daily FWC has a negative effect on daily work performance, psychological isolation in the process of FWC affect daily work performance play 
a regulatory role, daily focus in daily FWC influences the performance of work schedule play a mediating role in the process. But its performance measurement USES a task performance measurement scale, is only part of the job performance and task performance, and adopt the way of staff report to measurement of variables, there may be a self statement of prejudice. Experience the author through to the employees' daily work family conflict affect the daily work performance, to study the relationship between the work family conflict and work performance provides a new perspective

Studies have also made its relationship with job performance, find that there is no correlation between[19],the author USES is Australian physicians as the research object, and points out that different cultural background, the individual work family conflict in different ways may lead to the different WFC and work performance. At the same time the author measuring job performance scale including task performance and the performance of two parts around.

Because of work family conflict is work role and family role in some of the pressure of incompatible[3], some about employee job stress and job performance research is to study the relation between the work family conflict and work performance provides the beneficial enlightenment. In Lin WeiPeng et al.[20]the study of obstructive pressure and challenge to the work performance (task performance), there is no significant relationship between the high sense of responsibility of staff in challenging will significantly improve performance under pressure, but there is negative effect of employees' psychological distress at this time also will rise as. The article USES the resource allocation model[21]pointed out that the relationship between stress and performance may be triggered under certain conditions will influence (i.e., the regulation exists the relationship between the antecedent and consequence variables), so the research of the relationship between work family conflict and work performance, want to consider the role of individual traits as regulating variable.

\section{The Direction of Future Research}

Through the research about the relation between work family conflict and work performance, work family conflict has no marked impact on task performance, but in some studies found that work family conflict has a significant negative effect on contextual performance, so in the future research about work family conflict and job performance, one is thinking of work family conflict through mediation variables affect job performance, research on the impact of family conflict on job performance "black box" problem, for example the JD-R model[22] to study some possible variable mediation work family conflict influences the performance of work process; it is to consider whether the presence of situational variables (adjusting variable) will change the relationship between the work family conflict and work performance, such as resource allocation model[23]pointed out that the employee's individual characteristics will affect employee resource allocation process, so the staff after work family conflict, because of the different qualities of the individual process of resource allocation, work family conflict affect job performance may be different;

Three is in the research work family conflict and job performance,job performance can be divided into two dimensions, task performance and contextual performance for research. On the one hand, some scholars[24-26]ties to the research and the surrounding performance relationship is pointed out that only part of the job performance, peripheral performance in the future research will need to work and family relations with task performance and contextual performance were studied. On the other hand, some scholars in the study of relationship between job satisfaction and performance of surrounding points out: the relationship between job satisfaction and job performance is different, depends on whether the definition of job performance for task performance and surrounding performance,so the relationship between the work family conflict and work performance in different study each have differences, may be due to job performance is the definition of task performance or peripheral performance. Surrounding performance is defined as the employee role from outside to support the development of the organization behavior performance[27-28],so the future need to work family conflict and organizational citizenship behavior (OCB) of the relationship between research 
are also reviewed. Anyhow I found in the literature in recent years research work family conflict on job performance of the relationship between paper is less, the relationship between them is different, so to determine the relationship between the work family conflict and work performance also needs more empirical research.

\section{References}

[1] Mian Zhang.Work-family conflict and individual consequences[J].Journal of Managerail Psychology,2012,Vol.27 No.7: 696 - 713.

[2] Osman M.Karatepe,Georgiana Karadas.The effect of psychological capital on conflicts in the work-family interface,turnover and absence intention[J].International Journal of Hospitality Management,2014,43:132-143.

[3] Greenhaus,J.H.,\&Beutell,N.J.Sources of conflict between work and family roles[J].Academy of Management Review,1985,10:76-88.

[4] Frone, M. R., Russell, M., \& Cooper, M. L. Antecedents and outcomes of work-family conflict: Testing a model of the work-family interface. The Journal of Applied Psychology[J].1992,77, $65-78$.

[5] Van Steenbergen, E.F. and Ellemers, N."Is managing the work-family interface worthwhile? Benefits for employee health and performance", Journal of Organizational Behavior[J].2009.

Vol.30 No.5, pp.617-42.

[6] Liang Ding Jia,Jason D.Shaw.Anne S.Tsui,Tae-Youn Park.A social-structural perspective on employee-organization relationships and team creativity.Academy of Management Journal [J].2014,Vol.57,NO.3,8,69-891.

[7] Borma, W.C.and Motowidlo S.J.Expanding the criterion domain to include elements of contextual performance. Personnel Selection In Organization.San Francisco, CA:Jossey Bass, 1993

[8] Schmidt FL, Hunter JE, Outrbridge AN. Impact of job experience and ability on job knowledge, work sample performance and supervisory ratings of job performance. J Appl Psychol[J]. 1986;71:432-9.

[9] Wayne, J.H., Grzywacz, J.G., Carlson, D.S. and Kacmar, K.M."Work-family facilitation: a theoretical explanation and model of primary antecedents and consequences", Human Resource Management Review[J].2009, Vol. 17 No. 1, pp. 63-76.

[10] Hobfoll, S.E..Conservation of resources: a new attempt at conceptualizing stress. Am. Psychol[J].1989,44(3),513-524.

[11] Greenhaus, J. H., \& Powell, G. N.When work and family are allies: A theory of work-family enrichment. Academy of Management Review[J].2006,31,71-92.

[12] Bakker, A.B. and Demerouti, E. "The job demands-resources model: state of the art", Journal of Managerial Psychology[J].2007, Vol. 22 No. 3, pp. 309-328.

[13]Llorens, S., Bakker, A.B., Schaufeli, W. and Salanova, M. "Testing the robustness of the job demands-resources model", International Journal of Stress Management[J].2006, Vol. 13 No. 3, pp. 378-391.

[14] Osman M. Karatepe. The effects of work overload and work-family conflict on job embeddedness and job performance:The mediation of emotional exhaustion. International Journal of Contemporary Hospitality Management[J]. 2013, Vol.25 No.4, pp.614-634. 
[15] Heather N.Odle-Dusseau.Thomas W.Britt.Organizational Work-Family Rsources as Predictors of Job Performance and Attitudes:The Process of Work-Family Conflict and Enrichmene.Journal of Occuppational Health Psychology.2012,Vol.17,NO.1,28-40.

[16]Hyun Jung Choi,Young Tae Kim.Work-family conflict,work-family facilitation,and job outcomes in the Korean hotel industry.International Journal of Contemporary Hospitality Management [J].2012,Vol.24 NO.7

[17] Babin, B.J. and Boles, J.S. (1998), "Employee behavior in a service environment: a model and test of potential differences between men and women",Journal of Marketing,Vol.62, April,pp.77-91.

[18] Christoph Nohe,Alexandra Michel and Karlheinz Sonnt.Family-work conflict and job performance:A diary study of boundary conditions and mechanisms.Journal of Organizational Behavior[J]. 2013.

[19] Abbas,M.,Raja,U.,Darr,W.,Bouckenooghe,D.Combined effects of perceived politics and psychological capital on job satisfaction, turnover intentions, and performance[J].J.Manag,2012, Vol.27,less7,pp.696-713.

[20] Weipeng Lin,Jing Jing Ma,Lei Wang and Mo Wang. A double-edged sword: The moderating role of conscientiousness in the relationships between work stressors, psychological strain, and job performanc[J].Journal of Organizational Behavior,2014,DOI: 10.1002/job,1949.

[21] Grawitch,M.J.,Barber,L.K.,\&Justice,L.Rethinking the work-life interface:It's not about balance, it's about resource allocation[J].Applied Psychology:Health and Well-Being,2010,2:

127-159.

[22] Dawn S.Carlson.L.A.Witt.Suzanne Zivnuska K.Michele Kacmar Joseph G.Grzywacz.Supervisor Appraisal as the Link Between Family-Work Balance and Contextual Performance.J Bus Psychol[J],2008.

[23] Organ, D.W. Organizational citizenship behavior: The Good Soldier Syndrome. Lexington, MA: Lexington Books.1988.

[24] Bryan D.Edwards. Suzanne T.Bell.Winfred Arthur, Jr. and Arlette D. Decuir.Relationships between Facets of Job Satisfaction and Task and Contextual Performance.APPLIED PSYCHOLOGY: AN INTERNATIONAL REVIEW, 2008, 57 (3), 441-465.

[25] Osman M. Karatepe. The effects of work overload and work-family conflict on job embeddedness and job performance:The mediation of emotional exhaustion[J].International Journal of Contemporary Hospitality Management ,2013,Vol.25 No.4,pp.614-634.

[26] Samuel Aryee,Li-Yun Sun,ZhenXiong George Chen and Yaw A. Debrah.Abusive Supervision and Contextual Performance:The Mediating Role of Emotional Exhaustion and the Moderating Role of Work Unit Structure[J].Management and Organization Review,2008,4:3 393-411.

[27] Carlson,D.S.,Witt,L.A.,Zivnuska,S.,Kacmar,K.M.,\&Grzywacz,J.Supervisor appraisal as the ink between family-work balance and contextual performance[J].Journal of Business\& Psychology, 2008,23(1/2):37-49.

[28]Chen,D.J.Q.,Lim,V.K.G..Strength in adversity:the influence of psychological capital on job search[J].J.Org.Behav,2012,33 (6):811-839. 